\title{
Radiofrequency Ablation for Hepatic Malignancies: Is Needle Tract Cauterization Necessary for Preventing latrogenic Bleeding?
}

\author{
Yasunori Minami Sosuke Hayaishi Masatoshi Kudo \\ Department of Gastroenterology and Hepatology, Kinki University School of Medicine, Osakasayama, Japan
}

\section{Key Words}

Bleeding · Complications · Hepatic malignancy · Needle

tract cauterization · Radiofrequency ablation bleeding after RFA among hemodialysis patients. Irrespective of tract ablation being after RFA, iatrogenic hemorrhage appeared to be equivalent in this population.

c) 2013 S. Karger AG, Basel

\section{Introduction}

Percutaneous radiofrequency ablation (RFA) has been accepted as a safe and effective technique for the treatment of unresectable hepatic primary and metastatic malignancies [1-8]. Although the advantages of the use of RFA include low mortality and morbidity [9], early detection and treatment of complications is essential for a favorable RFA outcome.

General complications of RFA may be related to imaging-guided electrode placement (e.g. bleeding, arterialportal shunt, tumor seeding, pneumothorax), thermal therapy (e.g. nontarget thermal damage, grounding pad burns) or others (e.g. infection, infarction) [10-13]. Intraperitoneal bleeding is a serious complication that can result in mortality if not appropriately managed. This bleeding can develop from direct mechanical injury to the vascular structure by the radiofrequency (RF) needle electrode rather than from RF thermal injury to the vessel. Thus, the potential for bleeding depends on placement of the RF needle electrode without traversing major

\section{KARGER}

E-Mail karger@karger.com

www.karger.com/ddi
2013 S. Karger AG, Basel

0257-2753/13/0316-0480\$38.00/0
Masatoshi Kudo, MD, PhD

Department of Gastroenterology and Hepatology

Kinki University Faculty of Medicine

377-2 Ohno-Higashi, Osakasayama, Osaka 589-8511 (Japan)

E-Mail m-kudo@med.kindai.ac.jp 
Fig. 1. Linear hyperechogenicity following RFA was seen along the RF needle tract on B-mode US (arrows).

Fig. 2. An 80-year-old woman with an HCC. Contrast-enhanced CT showed that the ablated tumor (arrow) was not enhanced in segment VI of the liver. The ablated needle tract is depicted as a low-density line (arrowheads).
1

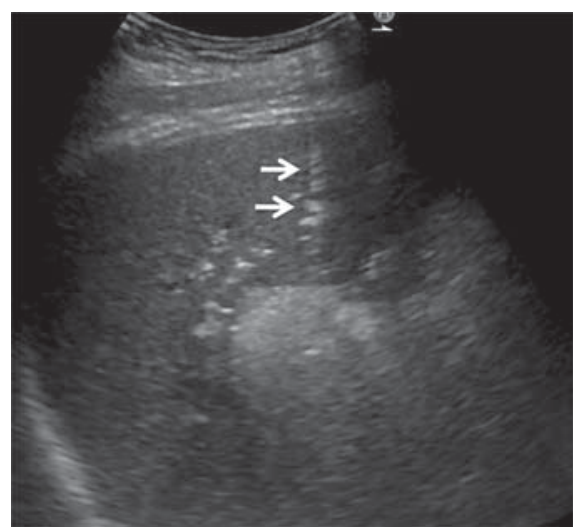

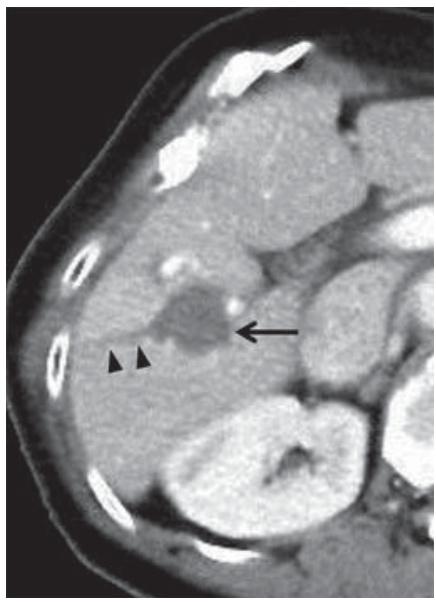

vessels and minimizing the amount of needle repositioning. In addition, cauterization of the needle tracts is thought to prevent bleeding after percutaneous RFA. However, to our knowledge, no previous studies have evaluated whether needle tract ablation actually contributes to reducing postprocedural bleeding. The purpose of this study was to assess whether intraperitoneal hemorrhage is prevented by intrahepatic tract ablation following RFA for hepatic malignancies.

\section{Materials and Methods}

\section{Patients}

Written informed consent to perform percutaneous RFA was obtained from all patients before treatment. This cohort study was conducted as a retrospective analysis of a prospective database in a single institution in which RFAs are routinely performed. After the introduction of RFA, our hospital has conducted procedures with or without intrahepatic tract ablation based on the preferences of two senior doctors. The records of consecutive patients who did or did not receive intrahepatic tract ablation following RFA or not between January 2007 and June 2011 at Kinki University Hospital were reviewed.

Hepatocellular carcinoma (HCC) was diagnosed based on three-phase contrast-enhanced CT findings such as positive enhancement in the arterial phase and washout in the equilibrium phase in patients with chronic liver disease. Liver metastases were diagnosed by ring enhancement on contrast-enhanced CT in patients with past cancer illness. Intrahepatic cholangiocarcinoma has been described as an irregular mass with markedly low attenuation, and minimal peripheral enhancement noted with ancillary findings in dilatation of the peripheral intrahepatic ducts. All patients met the following criteria for treatment with RFA: percutaneous accessibility of the tumors, absence of portal tumor thrombus and extrahepatic metastasis, prothrombin time ratio greater than $50 \%$, total bilirubin less than $4.0 \mathrm{mg} / \mathrm{dl}$ and platelet count greater than $30,000 / \mu l$.

RFA for Hepatic Malignancies
Equipment and Technique

B-mode ultrasound (US) scans were obtained using a LOGIQ 7 (GE Medical Systems, Milwaukee, Wisc., USA) or an EUB 8500 unit (HITACHI Medico, Tokyo, Japan). A multidetector CT (LightSpeed VCT, GE Medical Systems, Milwaukee, Wisc., USA) was used for diagnosis. Triple-phase contrast-enhanced CT scans were performed with a $5.0-\mathrm{mm}$ slice thickness at 30,60 and $180 \mathrm{~s}$ after initiating the injection of contrast media to obtain hepatic arterial-, portal venous- and equilibrium-phase images, respectively. A total of $100 \mathrm{ml}$ of nonionic contrast material containing $300 \mathrm{mg}$ of iodine per milliliter (Iomeprol, Eisai Co., Tokyo, Japan) was injected intravenously at a rate of $3 \mathrm{ml} / \mathrm{s}$ using an automatic power injector.

Patients were treated by RFA (Cooled-tip RF ablation system; Radionics, Burlington, Mass., USA). Twenty-centimeter-long, 17-gauge, monopolar internally cooled electrodes with 3 - or $2-\mathrm{cm}$ long exposed metallic tips (Radionics) were used to deliver RF energy. A 200-Watt, 480-kHz monopolar RF generator regulated by impedance (CC-1; Radionics) was used as the energy source.

RFA is mainly performed percutaneously under B-mode US guidance. If necessary, it can also be used under the guidance of contrast-enhanced US or virtual CT/MRI US. After RF energy was delivered, the hyperechoic zone appeared and gradually increased at the ablated site with monitoring to assess the ablation. The ablation was stopped when the entire target (including the safety margin) was completely covered by the zone of hyperechogenicity. In patients with tract ablation, RF energy was delivered again before removing the RF needle. Thereafter, the RF needle was slowly withdrawn so that the linear hyperechogenicity passed along the RF needle tract (fig. 1).

\section{Complications}

We assessed the laboratory data obtained before and after RFA, including serum hemoglobin level, prothrombin time and platelet count. Furthermore, we obtained a CT scan of the liver from 1-5 days (median 3 days) after RFA for the assessment of treatment response (fig. 2). The maximum thickness of perihepatic ascites was also recorded using CT scans obtained before RFA and after RFA (fig. 3). We considered hemoperitoneum to be present if the attenuation of ascites had increased around the perihepatic spaces in patients with serum hemoglobin levels reduced by more than $1.0 \mathrm{~g} / \mathrm{dl}$ in 1 day after RFA. 


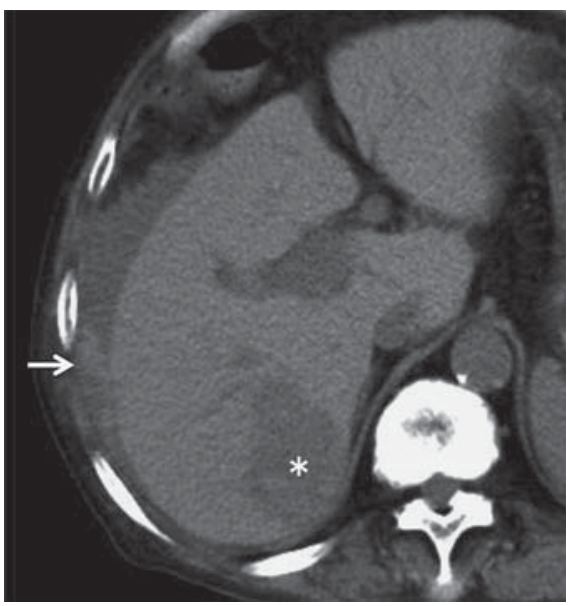

Fig. 3. A 65-year-old male hemodialysis patient with an HCC 2.5 $\mathrm{cm}$ in diameter. Plain CT detected the ablated area by RFA as low density $(*)$. Ascitic fluid appeared and intraperitoneal hemorrhage was depicted as high attenuation in ascites (arrow).

\section{Endpoint and Statistical Analysis}

The primary endpoint was the incidence of intraperitoneal hemorrhage after percutaneous RFA. The secondary endpoint was the occurrence of other postprocedural complications during an observation period of at least 1 month after RFA, including pleural effusion, ascites, pneumothorax, hemothorax, hepatic infarction, bile duct injury, pericardial effusion, gastrointestinal perforation and peritonitis, etc.

All values were expressed as mean \pm standard deviation (SD). Comparisons between the two groups were analyzed using Fisher's test. A $\chi^{2}$ test was used to compare differences in the use of RFA modifications among the four groups. $\mathrm{p}<0.05$ was considered statistically significant. Statistical analyses were performed using SPSS software (version 12.0; SPSS, Chicago, Ill., USA).

\section{Results}

\section{Baseline Characteristics of Patients}

In total, 1,072 patients with 1,730 hepatic malignancies were enrolled. The patient population included 685 men and 347 women. The maximal diameter of tumors ranged from 0.5 to $11 \mathrm{~cm}$ on dynamic CT. Of all 1,072 patients who underwent percutaneous RFA for the treatment, 922 (86.0\%) had HCC, $10(0.9 \%)$ had intrahepatic cholangiocarcinoma and the other 99 (9.2\%) had liver metastases, mostly from colorectal cancer.

Table 1 shows the characteristics of both groups. The distributions of sex and age were not different between the two groups. In the nonablation group, $316(83.2 \%)$, $62(16.3 \%)$ and $2(0.5 \%)$ patients were classified with
Table 1. Baseline clinical characteristics of patients

\begin{tabular}{|c|c|c|c|}
\hline Characteristics & $\begin{array}{l}\text { Nonablation group } \\
\text { (380 patients/ } \\
660 \text { nodules) }\end{array}$ & $\begin{array}{l}\text { Ablation group } \\
\text { (652 patients/ } \\
1,070 \text { nodules) }\end{array}$ & $\mathrm{p}$ value \\
\hline \multicolumn{3}{|l|}{ Sex, $n$} & 0.56 \\
\hline Male & 248 & 437 & \\
\hline Female & 132 & 215 & \\
\hline Age, years & $67.9 \pm 9.5$ & $69.0 \pm 9.8$ & 0.57 \\
\hline Range & $33-88$ & $32-90$ & \\
\hline \multicolumn{3}{|l|}{ Child-Pugh class, $\mathrm{n}$} & 0.23 \\
\hline A & 316 & 567 & \\
\hline B & 62 & 80 & \\
\hline $\mathrm{C}$ & 2 & 5 & \\
\hline \multicolumn{3}{|l|}{ Malignancies, $\mathrm{n}$} & 0.18 \\
\hline $\mathrm{HCC}$ & 331 & 591 & \\
\hline \multicolumn{4}{|l|}{ Intrahepatic } \\
\hline cholangiocarcinoma & 5 & 5 & \\
\hline Liver metastases & 45 & 54 & \\
\hline Tumor size, $\mathrm{cm}$ & $1.9 \pm 1.1$ & $1.7 \pm 1.1$ & 0.47 \\
\hline Range & $0.5-11$ & $0.5-8$ & \\
\hline \multicolumn{3}{|c|}{ Tumor location in liver subsegments, $\mathrm{n}$} & 0.19 \\
\hline Left lateral & 101 & 161 & \\
\hline Left medial & 92 & 116 & \\
\hline Right medial & 243 & 448 & \\
\hline Right lateral & 220 & 335 & \\
\hline Segment 1 & 4 & 10 & \\
\hline
\end{tabular}

Data are presented as mean \pm SD unless otherwise indicated.

Child-Pugh A, B and C liver function, respectively, whereas $567(87.0 \%), 80(12.3 \%)$ and $5(0.8 \%)$ patients in the ablation group were classified into Child-Pugh A, B and C, respectively. The proportions of patients with ChildPugh classification did not differ significantly.

Of 380 patients in the nonablation group, 596 patients underwent RFA for treatment of their primary liver tumor, including HCC $(87.1 \% ; 331 / 380)$ and intrahepatic cholangiocarcinoma $(1.3 \% ; 5 / 380)$. The other $45(11.8 \%)$ had liver metastases including colorectal cancer $(n=30)$, gastric cancer $(n=6)$, ovarian cancer $(n=1)$, pancreatic cancer $(n=$ $1)$, renal cell carcinoma $(n=1)$ and others $(n=6)$. In contrast, in the ablation group, 591 (90.6\%), 5 (0.8\%) and 54 (8.3\%) patients had HCC, intrahepatic cholangiocarcinoma and metastatic liver tumors, respectively. Secondary hepatic malignancies included colorectal cancer $(n=35)$, gastric cancer $(\mathrm{n}=4)$, ovarian cancer $(\mathrm{n}=2)$, pancreatic cancer $(n=2)$, renal cell carcinoma $(n=3)$ and others $(n=8)$.

The tumor size was not significantly different between the two groups. The mean tumor diameter was $1.9 \pm 1.1$ $\mathrm{cm}$ (range $0.5-11 \mathrm{~cm}$ ) in the nonablation group, and 1.7 $\pm 1.1 \mathrm{~cm}$ (range $0.5-8 \mathrm{~cm}$ ) in the ablation group. 
Table 2. Complications between groups

\begin{tabular}{lccl}
\hline Complications & $\begin{array}{l}\text { Nonablation } \\
\text { group } \\
(\mathrm{n}=380)\end{array}$ & $\begin{array}{l}\text { Ablation } \\
\text { group } \\
(\mathrm{n}=652)\end{array}$ & $\begin{array}{l}\mathrm{p} \\
\text { value }\end{array}$ \\
\hline Intraperitoneal hemorrhage & $6(0.9)$ & $4(1.1)$ & 0.90 \\
Pleural effusion & $27(7.1)$ & $31(4.8)$ & 0.11 \\
Serous ascites & $8(2.1)$ & $8(1.2)$ & 0.40 \\
Pneumothorax & $3(0.8)$ & $6(0.9)$ & 0.90 \\
Hemothorax & $3(0.8)$ & $4(0.6)$ & 0.95 \\
Hepatic infarction & $2(0.5)$ & $4(0.6)$ & 0.81 \\
Bile duct injury & 0 & $4(0.6)$ & - \\
Pericardial effusion & 0 & $1(0.2)$ & - \\
\hline
\end{tabular}

Values in parentheses are percentages.

\section{Intraperitoneal Hemorrhage}

Table 2 shows the complications in both groups in this study. No death was considered RFA related.

Procedural hemorrhage occurred in $10(0.93 \%)$ patients ( $\mathrm{HCC}, \mathrm{n}=8$; liver metastases, $\mathrm{n}=2$ ). In the nonablation group and the ablation group, the complication rates of hemorrhage were, respectively, 1.05\% (4/380) and $0.92 \%(6 / 652)$. No significant difference was observed in the incidence of iatrogenic bleeding $(\mathrm{p}=0.90)$. Fortunately, these patients did not need transcatheter arterial embolization for the treatment of iatrogenic bleeding after RFA, and improved with conservative therapy including blood transfusion. Of these 10 patients with bleeding, the platelet counts before ablation ranged from 48,000 to $325,000 / \mu \mathrm{l}$ (mean \pm SD $12,600 \pm 8,100$ ). The prothrombin time before ablation was $67-103 \%$ (mean \pm SD $85.0 \pm$ 10.1), and all patients were classified as Child-Pugh grade A ( 5 points, $n=7 ; 6$ points, $n=3$ ). The mean tumor diameter was $2.1 \pm 0.9 \mathrm{~cm}$ (range $0.9-11 \mathrm{~cm}$ ).

Among the 15 hemodialysis patients in this study, hemorrhage was seen in $2(13.3 \%)$, whereas $8(0.79 \%)$ patients with bleeding were nonhemodialysis $(\mathrm{p}=0.0002)$.

\section{Other Complications}

The complications of RFA excluding hemorrhage were pleural effusion, serous ascites, pneumothorax, hemothorax, hepatic infarction, bile duct injury and pericardial effusion (table 2). Gastrointestinal perforation, peritonitis and tumor seeding by RFA was not observed in this study. No significant differences were observed in the incidences of these complications between the two groups. Three patients with pneumothorax (nonablation group, $\mathrm{n}=1$; ablation group, $\mathrm{n}=2$ ) were treated with chest tube drainage, and the fluid was drained in a patient with pericardial effusion. The other patients with complications subsided after conservative treatments.

\section{Discussion}

The overall rate of intraperitoneal hemorrhage for 1,730 ablated lesions was $0.93 \%$ in our study, a value that coincides with other experiences. The rates of iatrogenic bleeding treated with percutaneous RFA have been reported to be $0.32-1.6 \%$ [14-21]. Arterial bleeding causes robust hemorrhage that could contribute to mortality, and transcatheter arterial embolization would be needed for interventional hemostasis.

When an RF electric current meets tissue resistance, the electrical energy is converted into thermal energy via molecular agitation or ohmic heating (direct heating). This heat could cause denaturation of vessels and blood coagulation. Thus, cauterization of the needle tracts is considered to prevent intraperitoneal bleeding through the injured vessels. Laeseke et al. [22] reported that biopsy sites after ablation had significantly less blood loss than did control biopsy sites using porcine liver or kidney. However, the volume of blood loss was very low, at less than $3 \mathrm{~g}$, in the ablation group and control group from their data. Therefore, it could be expected that a RFA needle laparotomy technique could decrease nonarterial bleeding from the liver after a needle biopsy. Regardless of the procedure of hemostasis, nonarterial bleeding will stop in time without clinical problems.

In this study, no significant differences were observed in the incidence of iatrogenic bleeding between the nonablation group and the ablation group. Without needle tract cauterization, hemostasis can be achieved in several ways: (1) closure of the electrode puncture wound, (2) vascular spasm and (3) blood clotting or coagulation. Perihepatic bleeding might occur with disorders of these steps even in patients with tract ablation. It is considered from our results that needle tract cauterization does not contribute directly to hemostasis. Thus, intraperitoneal hemorrhage appeared to be equivalent regardless of nontract ablation following RFA.

The 10 patients with peritoneal hemorrhage were classified as Child-Pugh grade A, while many Child-Pugh $\mathrm{B} / \mathrm{C}$ patients were included in this study. Intraperitoneal hemorrhage is usually related to mechanical injuries caused by the RF electrode traversing a vessel or thermal injuries sustained during ablation $[15,16]$. The incidence of bleeding was thus not necessarily related to liver dys- 
function, low levels of the platelets or the prothrombin time. However, our results showed a high incidence of bleeding among hemodialysis patients. Bleeding is common for patients with chronic renal failure, and is caused by the following: (1) increased capillary fragility, (2) disturbance of blood coagulation and (3) administration of heparin during dialysis. Therefore, we have to perform RFA carefully in hemodialysis patients. However, further studies are needed to clarify whether the iatrogenic hemorrhage could be prevented by needle tract cauterization following RFA in hemodialysis patients.

Our study was limited by its retrospective and nonrandomized design, leading to possible inaccurate or incomplete data collection, which may result in an underestimation of complications. The nonrandomized retrospective design is also known to be associated with possible selection case bias.

In conclusion, iatrogenic bleeding after RFA could contribute to several complicated situations including elevated blood pressure, the condition of injured arteries (branching vessel level, depth from the liver surface, capillary fragility), or past history of disease (chronic renal failure, chronic liver disease). Irrespective of needle tract cauterization following RFA, iatrogenic hemorrhage appeared to be equivalent in this population.

\section{Disclosure Statement}

The authors have no conflicts of interest to declare.

\section{References}

1 Rossi S, Di Stasi M, Buscarini E, Cavanna L, Quaretti P, Squassante E, Garbagnati F, Buscarini L: Percutaneous radiofrequency interstitial thermal ablation in the treatment of small hepatocellular carcinoma. Cancer J Sci Am 1995;1:73-81.

2 Kudo M: Local ablation therapy for hepatocellular carcinoma: current status and future perspective. J Gastroenterol 2004;39:205214.

-3 Shiina S, Teratani T, Obi S, Sato S, Tateishi R, Fujishima T, Ishikawa T, Koike Y, Yoshida $\mathrm{H}$, Kawabe T, Omata M: A randomized controlled trial of radiofrequency ablation with ethanol injection for small hepatocellular carcinoma. Gastroenterology 2005;129:122-130.

4 Llovet JM, Bruix J: Novel advancements in the management of hepatocellular carcinoma in 2008. J Hepatol 2008;48(suppl 1):S20-S37.

5 Lencioni R, Crocetti L: Local-regional treatment of hepatocellular carcinoma. Radiology 2012;262:43-58.

6 Mahnken AH, Pereira PL, de Baère T: Interventional oncologic approaches to liver metastases. Radiology 2013;266:407-430.

7 Minami Y, Kudo M: Radiofrequency ablation of liver metastases from colorectal cancer: a literature review. Gut Liver 2013;7:1-6.

-8 Lin S, Hoffmann K, Schemmer P: Treatment of hepatocellular carcinoma: a systematic review. Liver Cancer 2012;1:144-158.

9 Lin SM: Local ablation for hepatocellular carcinoma in Taiwan. Liver Cancer 2013;2:7383.

10 Tateishi R, Shiina S, Teratani T, Obi S, Sato S, Koike Y, Fujishima T, Yoshida H, Kawabe T, Omata M: Percutaneous radiofrequency ablation for hepatocellular carcinoma: an analysis of 1,000 cases. Cancer 2005;103:1201-1209.
Livraghi T, Meloni F, Di Stasi M, Rolle E, Solbiati L, Tinelli C, Rossi S: Sustained complete response and complications rates after radiofrequency ablation of very early hepatocellular carcinoma in cirrhosis: is resection still the treatment of choice? Hepatology 2008;47:8289.

12 Sato M, Tateishi R, Yasunaga H, Horiguchi H, Yoshida H, Matsuda S, Koike K: Mortality and morbidity of hepatectomy, radiofrequency ablation, and embolization for hepatocellular carcinoma: a national survey of 54,145 patients. J Gastroenterol 2012;47:1125-1133.

13 Hasegawa K, Kokudo N, Makuuchi M, Izumi N, Ichida T, Kudo M, Ku Y, Sakamoto M, Nakashima O, Matsui O, Matsuyama Y: Comparison of resection and ablation for hepatocellular carcinoma: a cohort study based on a Japanese nationwide survey. J Hepatol 2013; 58:724-729.

14 Livraghi T, Solbiati L, Meloni MF, Gazelle GS, Halpern EF, Goldberg SN: Treatment of focal liver tumors with percutaneous radio-frequency ablation: complication encountered in a multicenter study. Radiology 2003;226: 441-451.

15 Rhim H, Dodd GD 3rd, Chintapalli KN, Wood BJ, Dupuy DE, Hvizda JL, Sewell PE, Goldberg SN: Radiofrequency thermal ablation of abdominal tumors: lessons learned from complications. Radiographics 2004;24: 41-52.

16 Chen MH, Yang W, Yan K, Gao W, Dai Y, Wang YB, Zhang XP, Yin SS: Treatment efficacy of radiofrequency ablation of 338 patients with hepatic malignant tumor and the relevant complications. World J Gastroenterol 2005;11:6395-6401.
7 Carrafiello G, Laganà D, Ianniello A, Craparo G, Recaldini C, Lumia D, Dionigi G, Cuffari S, Fugazzola C: Bleeding after percutaneous radiofrequency ablation: successful treatment with transcatheter embolization. Eur J Radiol 2007;61:351-355.

-18 Kasugai H, Osaki Y, Oka H, Kudo M, Seki T, Osaka Liver Cancer Study Group: Severe complications of radiofrequency ablation therapy for hepatocellular carcinoma: an analysis of 3,891 ablations in 2,614 patients. Oncology 2007;721:72-75.

19 Poggi G, Riccardi A, Quaretti P, Teragni C, Delmonte A, Amatu A, Saini G, Mazzucco M, Bernardo A, Palumbo R, Canto A, Bernieri S, Bernardo G: Complications of percutaneous radiofrequency thermal ablation of primary and secondary lesions of the liver. Anticancer Res 2007;27:2911-2916.

20 Takaki H, Yamakado K, Nakatsuka A, Yamada T, Shiraki K, Takei Y, Takeda K: Frequency of and risk factors for complications after liver radiofrequency ablation under CT fluoroscopic guidance in 1,500 sessions: single-center experience. AJR Am J Roentgenol 2013; 200:658-664.

21 Koda M, Murawaki Y, Hirooka Y, Kitamoto M, Ono M, Sakaeda H, Joko K, Sato S, Tamaki K, Yamasaki T, Shibata $\mathrm{H}$, Shimoe T, Matsuda T, Toshikuni N, Fujioka S, Ohmoto K, Nakamura S, Kariyama K, Aikata H, Kobayashi Y, Tsutsui A: Complications of radiofrequency ablation for hepatocellular carcinoma in a multicenter study: an analysis of 16,346 treated nodules in 13,283 patients. Hepatol Res 2012;42:1058-1064.

22 Laeseke PF, Winter TC 3rd, Davis CL, Stevens KR, Johnson CD, Fronczak FJ, Webster JG, Lee FT Jr: Postbiopsy bleeding in a porcine model: reduction with radio-frequency ablation - preliminary results. Radiology 2003;227:493-499. 